\title{
Por uma agenda de pesquisa em democracia eletrônica
}

\author{
Danilo Rothberg \\ Bolsista Prodoc/Capes no Programa de Mestrado em \\ Ciência, Tecnologia e Sociedade \\ Universidade Federal de São Carlos
}

\section{Resumo}

Os mecanismos de participação democrática proporcionados pelas novas tecnologias de informação e comunicação representam a possibilidade de alargamento do espaço público. A criação de canais como fóruns de discussão e consultas públicas online em websites governamentais significa um avanço promissor, mas com resultados que ainda não foram estudados devidamente. Este artigo revisa teorias que têm sustentado investigações na área, caracteriza estudos recentes no Brasil e no âmbito da União Européia e apresenta contribuições para a construção de uma agenda de pesquisa atual que considere o potencial das novas tecnologias para o aprofundamento da democracia e indique caminhos para avaliar se o suporte tecnológico é adequadamente explorado a fim de subsidiar uma inserção eficaz nos processos de definição e avaliação de políticas públicas.

Palavras-chave: democracia eletrônica, cidadania, esfera pública, democracia deliberativa, discussão online

\begin{abstract}
The mechanisms of democratic participation provided by the new technologies of information and communication represent the possibility of widening the public space. The creation of channels such as online discussion foruns ans public consultations brings a promissing advance, but their results were not satisfactorily studied yet. This paper revises theories which have been supported investigations in this field, characterizes recent studies in Brazil and presents contributions to the an up-to-date research agenda, which considers the potential of the new technologies to the strengthening of democracy and indicates paths to evaluate if the technological support is adequately explored in order to help an effective insertion in the processes of definition and evaluation of public policies.
\end{abstract}

Keywords: e-democracy, citizenship, public sphere, deliberative democracy, online discussion 


\section{Introdução}

Os mecanismos de participação democrática proporcionados pelas novas tecnologias representam a possibilidade de alargamento do espaço público e a conseqüente inserção organizada de setores diversos nos processos de definição de políticas públicas. No Brasil, este pressuposto é reconhecido pelas diretrizes de governo eletrônico, que afirmam o papel do Estado na gestão tecnológica de maneira a incentivar formas participativas de realização da democracia digital.

Neste contexto, a criação de canais tais como fóruns de discussão e consultas públicas online em websites governamentais significa um avanço promissor, mas com resultados ainda não estudados devidamente.

Se, de um lado, a inserção pode se dar com competência e domínio conceitual, por outro, é possível que a legitimidade da participação seja comprometida por deficiências como o estreitamento das questões postas em debate, a insuficiência das informações disponíveis para subsidiar as consultas, a limitação das perspectivas colocadas para orientar o discernimento sobre as questões consultadas e a inadequada mediação entre os participantes.

Mas é preciso considerar que, no âmbito da democracia digital em uma sociedade informacional em rede, a tecnologia pode ser explorada a fim de oferecer subsídios para a avaliação de questões complexas, compondo um sistema de expressão e intercâmbio de informações e de posicionamentos institucionais e setoriais capaz de gerar acumulação de capital social e, assim, trazer ganhos de eficiência à implementação de políticas públicas em setores diversos.

Este artigo revisa teorias que têm sustentado investigações na área, caracteriza estudos recentes e apresenta contribuições para a definição de uma agenda de pesquisa atual, que considera o potencial das novas tecnologias de informação e comunicação para o aprofundamento da democracia e indica caminhos para avaliar se o suporte tecnológico é adequadamente explorado a fim de subsidiar a inserção eficaz dos setores consultados nos processos de agenda e definição de políticas públicas.

\section{Engajamento e deliberação}

Construir e manter canais de interatividade que explorem o potencial das novas tecnologias para o aperfeiçoamento de processos de gestão é um dos maiores desafios dos governos democráticos da atualidade. Subjacente à busca por meios de utilização inteligente da internet nesse contexto está uma percepção simples: as decisões políticas tomadas com a legitimidade obtida através de consultas públicas online e outros meios de envolvimento dos cidadãos com a 
ROTHBERG, D. Por uma agenda de pesquisa em democracia eletrônica...

política pela rede, como fóruns virtuais, tendem a diminuir eventuais resistências a mudanças e novas circunstâncias e, assim, podem trazer ganhos de eficiência na gestão pública.

Este pressuposto pode ser suportado pela literatura sobre capital social, entendido como a qualidade obtida a partir do fortalecimento generalizado do exercício dos direitos civis e políticos em uma coletividade que situe a participação popular como prioridade nos processos democráticos de definição e implementação de políticas públicas (HALL e TAYLOR, 2003; KLIKSBERG, 1999; ABU-EL-HAJ; 1999). Deste âmbito teórico vem a idéia de que uma burocracia governamental pode não dispor, sozinha, do poder político exigido para conduzir políticas públicas bem-sucedidas. Desta forma, o reconhecimento da necessidade de incluir os cidadãos na formulação de políticas não significa perda de autonomia, mas ampliação da capacidade de produzir a resposta desejada pelas comunidades. Segundo este raciocínio, acredita-se que seja possível obter, como resultado do incremento de capital social, a eficiência da gestão pública. A participação na definição de políticas, ao envolver setores centrais para a questão em debate, é capaz de reduzir resistências e, portanto, também os custos de implantação de medidas legais e administrativas.

O capital social, como ingrediente do engajamento cívico, manifesta-se nas "características da vida social — redes, normas e confiança - que habilitam os participantes a agir juntos com mais eficiência para buscar objetivos compartilhados", salienta Putnam (1995, p. 664-665, tradução do autor). Essa natureza de capital advém, segundo Coleman (1988), das relações de confiança estabelecidas entre atores sociais, teoricamente resultantes de articulações possíveis em três níveis: "obrigações e expectativas", que são compartilhadas em graus dependentes da confiabilidade proporcionada por dada estrutura social, a "capacidade do fluxo de informações" existente em um contexto social e "normas acompanhadas por sanções", capazes de incentivar determinados comportamentos e coibir outros (COLEMAN, 1988, p. S119, tradução do autor).

A respeito especificamente da "capacidade do fluxo de informações" na criação de capital social, deve-se considerar que, se a internet já foi considerada um fator potencialmente prejudicial ao processo de formação da consciência sobre questões políticas (porque possibilita o consumo massivo de informação ligada ao entretenimento), atualmente se acredita, no entanto, que a possibilidade de a rede resultar em fortalecimento cívico está ligada ao tipo de uso que dela se faz (SHAH et al., 2005). Assim, a busca de informações e a expressão em consultas e fóruns online, se realizadas com critério e interesse pela cidadania, tendem a ser fatores de politização.

O entendimento atual dos usos da internet vem de pesquisas que captaram variedade semelhante de possibilidades de comportamento de consumo em meios tradicionais como TV e veículos impressos, indicam Shah et al. (2005). NesSas 
mídias, o consumo motivado pela busca de informações para o exercício de alguma forma de vigilância sobre o governo foi associado ao engajamento cívico, resultante de conhecimento crescente sobre a gestão de políticas públicas, enquanto a busca de infotainment (informação ligada ao entretenimento) foi ligada à apatia e ao desinteresse cívico. No consumo de conteúdo por meio da internet, os pesquisadores viram tendências análogas, o que sinaliza que o veículo, por si só, não determina a natureza do uso, mas sim pode reforçar comportamentos préexistentes.

Ou seja, o potencial da internet para ampliar o nível de informação política é limitado por fatores como o desinteresse das pessoas ou a inabilidade em assimilar grandes volumes de dados, indica Polat (2005). Não obstante, a rede pode trazer oportunidades decisivas para aqueles que estiverem dispostos ou forem incentivados a se engajar civicamente, fornecendo informação relevante e suporte para discussões coerentes em torno de eixos determinados - ao passo, no entanto, que a possibilidade de ela reverter a tendência de distanciamento entre os cidadãos e a política ainda precisa ser mais bem estudada.

Mas, sobretudo, tem sido considerado que a internet, como meio, oferece potencial específico de politização, em função de suas características técnicas e de conteúdo, diferentemente do meio impresso ou da TV. "A internet pode promover engajamento cívico em parte devido à sua flexibilidade ao permitir aos usuários acessar informações sob demanda, receber notícias de maneira conveniente, aprender sobre diversos pontos de vista, personalizar conteúdo de acordo com seus interesses e avançar em profundidade em torno de assuntos de interesse", salientam Shah et al. (2005, p. 535, tradução do autor). E, de fato, no estudo empírico realizado pelos autores, a internet, como recurso para obtenção de informação e como suporte de fóruns de discussões, mostrou-se mais fortemente associada ao engajamento cívico do que o consumo de mídias impressas e televisuais e a discussão face a face.

Seja na forma de uma atuação positiva sobre a formação da consciência política ou servindo como fonte inesgotável de entretenimento evasivo, as possibilidades de uso da internet e seu potencial papel de fortalecimento de capital social e engajamento cívico figuram como objeto de estudo relevante, especialmente nos casos em que a utilização da internet ocorre como forma de mediação voltada para fazer dela um instrumento de comunicação efetiva em duas vias, na forma de redes criadas e mantidas pelas instituições democráticas formais. "Redes comunitárias, sustentadas por espaços virtuais de deliberação pública, podem contribuir para a criação de capital social", avalia Frey (2003, p. 182). 0 desenvolvimento das oportunidades precisa ser acompanhado de maneira sistemática, já que o "desenho institucional precisa desempenhar um papel importante na provisão de canais de participação e oportunidades de interação social" (FREY, 2003, p. 182). 
ROTHBERG, D. Por uma agenda de pesquisa em democracia eletrônica...

Os benefícios esperados com a implantação de tecnologias e práticas de democracia digital também podem ser caracterizados através do conceito habermasiano de esfera pública. Particularmente, vale resgatar o que essa noção representa hoje para o empreendimento de pensar novos meios de ligação entre uma sociedade civil dispersa e a natureza de democracia representativa que se constitui formalmente na atualidade. O cenário parece caracterizado pela apatia de parcelas consideráveis da sociedade, realidade que então se procura enfrentar com medidas de incentivo à participação, que podem servir-se das novas tecnologias com método e criatividade.

O resultado pode ser a aproximação de um sistema político ao modelo de democracia deliberativa (HABERMAS, 1995; HELD, 1996). Conforme enfatiza Maia, nesse modelo "é condição necessária para a obtenção de legitimidade que o exercício do poder e a organização das principais instituições sociais sejam o resultado do procedimento de deliberação na esfera pública" (MAIA, 2002, p.49).

Aqui, a participação deve ser entendida como instrumento necessário à deliberação e possibilidade de renovação da democracia. Isso porque "a democracia deliberativa vai dar centralidade à questão da participação com base em uma nova concepção acerca da legitimidade política", analisa Lüchmann (2007, p. 143). O caráter deliberativo é proposto como meio de superar imperfeições da democracia representativa e a diminuição da legitimidade do processo de decisão política: "a democracia deliberativa advoga que a legitimidade das decisões políticas advém de processos de discussão que, orientados pelos princípios da inclusão, do pluralismo, da igualdade participativa, da autonomia e do bem-comum, conferem um reordenamento na lógica de poder tradicional" (LÜCHMANN, 2007, p. 143).

Não há necessariamente sob este raciocínio uma oposição entre participação e representação como meios ideais de realização democrática. Conforme indica Lüchmann (2007, p. 158) a respeito das experiências brasileiras de orçamento participativo, a representação pode ser fortalecida justamente com o exercício da participação. Tal parece ser também o caso da deliberação online, sustentam Coleman e Gøtze: "fortalecer a representação através de um processo de contínua discussão e consulta digital significa (...) conferir aos cidadãos o domínio de sua representação". Os indivíduos podem então deixar de ser meros consumidores de políticas, para se tornarem "acionistas" delas, assumindo "responsabilidades e obrigações" da cidadania típicas de uma sociedade em rede (COLEMAN e GØTZE, 2002, p. 23, tradução do autor).

A internet pode ser apreciada neste cenário em seu potencial de transformação do nível de informação disponível para a deliberação democrática, corrigindo eventuais insuficiências do sistema de mídia tradicional na provisão de informação política. "Se a informação é suficientemente ampla, permitindo aos representantes do governo, porta-vozes de causas cívicas e grupos de interesse 
defender suas posições de modo inteligente e esclarecedor, então os cidadãos podem decidir sobre as políticas que preferem", aponta Maia (2002, p. 51). "Mas se a informação é controlada, imprecisa ou inconsistente, então o debate pode ser manipulado e as alternativas se estreitam através da desinformação" (p. 51).

Se, com a valorização da idéia de esfera pública, abre-se "espaço para uma nova forma de relação entre racionalidade e participação", conforme querem Avritzer e Costa (2004, p. 706), os esforços pelo fortalecimento dos sistemas democráticos não podem ignorar o fato de que é preciso, antes, a multiplicação dos espaços onde pode se realizar a democracia.

O exame das possibilidades atuais encontra os caminhos trazidos pelo advento da sociedade informacional em rede, que significa etapa radicalmente nova de um percurso há muito iniciado, no qual a busca pelo envolvimento permanente dos cidadãos com a política é uma continuação natural de meios tradicionais, como eleições e plebiscitos.

Afinal, a difusão da informação por meio das novas tecnologias tem o potencial de provocar uma profunda politização da sociedade. "Os diferentes âmbitos da sociedade se fazem mais interdependentes, os mundos da economia e da tecnologia dependem mais que nunca do governo e, portanto, dos processos políticos", resume Castells (1996, p. 5).

O próprio Estado vai aí figurar em seu potencial de empregar as tecnologias como fonte de mudança e adaptação às exigências da nova sociedade informacional. Um Estado forte e democrático deve resistir à tendência de permitir que o aparato tecnológico resulte em uma concentração de poder ainda maior. Castells (1996) lembra que controlar a ciência e a técnica das tecnologias da informação equivale a exercer uma forma de domínio singular, e o Estado deve preservar seu papel estratégico como fonte de poder na sociedade. Assim, um Estado que não seja capaz de assimilar, em suas diversas esferas, as transformações tecnológicas pode se enfraquecer, tanto do ponto de vista da produção material quanto da perspectiva do domínio institucional e simbólico.

Qual é, então, o papel do Estado no desenvolvimento de tecnologias que permitam o aprofundamento dos espaços democráticos? Uma resposta adequada vai assinalar que caberá uma intervenção orientada à construção de uma esfera pública ampliada. A tecnologia que permite a conexão simultânea entre milhões e o conseqüente fluxo incessante de informações permitiria, neste contexto, a concretização última do ideal de esfera pública. Habermas (1984) seria atualizado, reafirmando-se que "o espaço público continua estabelecendo, como órbita insubstituível de constituição democrática da opinião e da vontade coletivas, a mediação necessária entre a sociedade civil, de um lado, e o Estado e o sistema político, de outro", sustentam Avritzer e Costa (2004, p. 708).

$E$, se a posição em uma rede determina as chances de se exercer influência real sobre os processos que por ela transitam, no Estado são mais uma vez 
ROTHBERG, D. Por uma agenda de pesquisa em democracia eletrônica...

colocadas as expectativas de construção de um instrumento de promoção de igualdade, pois as redes são "formadas em sociedades desiguais, segmentos da sociedade, grupos sociais e individuais, a distinção social mais importante se refere à posição dada em uma rede", salienta Castells (1996, p. 25).

\section{Microesferas públicas}

O conceito de esfera pública tem sido reformulado para abranger a diferenciação trazida pelos espaços de conversação na internet. Gitlin (1998), por exemplo, lembra que e-mails, blogs, chats, petições e fóruns online significam a possibilidade de que diversos públicos se organizem e dialoguem, dando corpo a microesferas públicas que representam a chance de instauração de um novo patamar de democracia.

A idéia de microesferas públicas resulta de uma reelaboração da noção habermasiana, ocorrida nos últimos vinte anos. No percurso de reformulação, a idealização de uma circunstância histórica (o espaço de deliberação da burguesia no século XVIII) é questionada para dar lugar a um enfrentamento que passa a levar em conta a realidade objetiva da organização social contemporânea.

Segundo Fraser, na esfera pública burguesa pensada por Habermas (1984), as desigualdades de origem são temporariamente suspensas no fórum de discussão pública. O enfrentamento se dá no plano das idéias, não cabendo ali distinções relativas à procedência social do emissor. Isso garantiria a igualdade de participação.

No entanto, Fraser sustenta que a suspensão momentânea das desigualdades é apenas formal e, obviamente, não elimina o efeito de estruturas erguidas historicamente. Desta forma, na prática, as distinções de origem fundamentam diferentes níveis de poder e status com que cada posição é expressa no fórum público. Opiniões ancoradas na riqueza material de seu emissor tendem a prevalecer no debate livre, enquanto as perspectivas de indivíduos sem posses ou em posições subalternas no mercado de trabalho formal ou informal serão ofuscadas, assim como as de mulheres, negros e minorias étnicas.

Fraser critica a legitimidade dos métodos de fóruns nos quais as desigualdades são dissimuladas a pretexto de facilitar a discussão: "Nós deveríamos questionar se é possível, até mesmo em princípio, aos interlocutores deliberar como se fossem pares sociais em arenas discursivas especialmente designadas, quando elas estão situadas em contextos sociais maiores atravessados por relações estruturais de dominação e subordinação", salienta a autora (FRASER, 1990, p. 65, tradução do autor).

A ocultação das diferenças serve principalmente à hegemonia dos mais fortes economicamente, que usam seu peso para conferir mais poder às suas 
concepções culturais que, adiante, vão se tornar igualmente prevalecentes. Embora os mais fracos tenham, aparentemente, as mesmas oportunidades para se expressar, sua subalternidade é indissociável de sua palavra manifesta e prejudica as chances de seu discurso ser efetivamente levado em conta na disputa aberta entre posições discordantes. A comunicação entre as partes vai ocorrer de maneira artificial, tornando-se possível somente em função da indiferença falsamente sustentada em torno de distinções da maior importância, o que compromete a autenticidade do diálogo e coloca em risco a viabilidade das estratégias então elaboradas.

É verdade que, no contexto da esfera pública burguesa, a inspiração liberal determina que o apagamento das diferenças nas posições iniciais do debate é necessário para que a discussão seja orientada à consecução do bem comum. Quando se supõe ser possível atingir uma solução identificada com o benefício de cada um e de todos ao mesmo tempo, uma decorrência natural é querer que todos abandonem suas posições de classe etc na porta de entrada do debate, para daí ingressarem em uma esfera sumariamente associada à realização do bem-estar universal.

No entanto, denuncia Fraser (1990), a idéia de que os interesses privados possam ser anulados quando adentram a esfera pública, para daí surgir a busca pelo bem comum apenas esconde o fato de que, na prática, eles ainda estarão lá, guiando a discussão de forma subterrânea em benefício próprio, e ainda mais fortalecidos porque disfarçados sob a imagem de neutralidade. A mistificação do que vem oportunamente a ser chamado de bem comum serviria a setores privados que se apressam para forjar seus próprios interesses como interesses da coletividade.

Desta forma, a saída é admitir a existência de múltiplos públicos competitivos (ou diversas microesferas públicas), cada um com suas pretensões de validade, chamando para si o domínio da compreensão de determinada questão em debate. Nesse caso, ao invés de uma única esfera pública que exige o esmaecimento das diferenças como condição de participação e a conseqüente aceitação dos termos dominantes no debate, tem-se a diversidade de grupos que organizam seu discurso justamente a partir da afirmação da sua variedade. Ou seja, sua diferença é tematizada. Ao invés de forçar o consenso, o debate aclara as singularidades em disputa.

As estratégias de mediação das participações em um fórum ou consulta pública online devem, assim, serem implementadas com a consciência de que é preciso saber ouvir as diferenças e perceber como elas atravessam todo o debate e cada expectativa dos participantes. Na esfera online, é preciso desenvolver formas de discussão sintonizadas aos ideais de deliberação democrática, que envolvem, sintetiza Dahlberg (2001), a troca e a crítica de argumentos refletidos, a aceitação do papel de participante em uma deliberação (e a conseqüente disposição para 
ROTHBERG, D. Por uma agenda de pesquisa em democracia eletrônica...

tentar compreender os argumentos alheios) e reflexão sobre a legitimidade das demandas próprias em função das expectativas dos outros. Os debates devem ser plurais, permitindo a expressão de perspectivas variadas para que os participantes sejam levados a apreciar a justeza de seus anseios em relação às políticas públicas, diante das aspirações alheias.

Se conceitualmente isto pode parecer simples, empiricamente as dificuldades são grandes. Como proceder à organização de um debate com o objetivo de fortalecer micro-esferas públicas? Quais são os formatos mais adequados para que cada segmento depure suas perspectivas na discussão online e enriqueça o debate? Como intermediar os confrontos, explorando o potencial das tecnologias de comunicação e informação, a fim de garantir oportunidades iguais de expressão? Como permitir o questionamento da validade das diversas demandas com lisura e respeito? O desenho de dada solução vai influenciar a qualidade do debate, por isso devem-se estudar as saídas possíveis e verificar as características dos formatos atuais.

Conforme indica Coleman (2002), a construção de vínculos entre indivíduos, entidades, instituições e setores, então aproximados por interesses em comum, através de discussões online em torno da necessidade de avanços legais, políticos e institucionais é um dos benefícios em termos de engajamento cívico que podem ser obtidos com o uso adequando das novas tecnologias.

O recrutamento de experiências e conhecimentos específicos para determinados debates é um resultado possível e desejável: propostas de fóruns sérios em torno de questões colocadas com clareza e organização, além de mediação adequada, tendem a atrair a participação de pessoas e setores com expertise sobre o assunto em questão, o que pode levar ao incremento generalizado da qualidade da discussão. Outro benefício é o próprio aprendizado sobre como e o quê significa deliberar de maneira produtiva, o que envolve reconhecer a complexidade das questões envolvidas no percurso de definição e avaliação de políticas públicas. A qualidade das soluções tecnológicas então adotadas será determinante nesse processo. 


\section{Experiências e pesquisas no Brasil e no âmbito da União Européia}

Para avaliar o desempenho dos governos na gestão de seus websites governamentais, têm sido aplicadas no Brasil metodologias de pesquisa distintas. No país, oportunidades como consultas e fóruns online são raras, mas já acontecem em número suficiente para justificar estudos específicos, focados exatamente na qualidade do debate então proporcionado. É verdade que, no entanto, se a maioria dos websites governamentais esgota-se na provisão de informações e serviços, sem mecanismos que sustentem formas de deliberação democrática, as pesquisas têm, no Brasil, se limitado ao exame do desenho das ferramentais usualmente encontradas.

$\mathrm{Na}$ área de gestão da informação, estão investigações que focam dimensões de conteúdo, usabilidade e funcionalidade, verificando, de maneira geral, a oferta de informações institucionais e a qualidade e quantidade de prestações de serviços ao usuário (BARBOZA, NUNES E SENA, 2000; VILELLA, 2003; SIMÃO E RODRIGUES, 2005; D'ANDRÉA, 2006; FURQUIM, 2004).

$\mathrm{Na}$ intersecção entre comunicação e ciência política, estão estudos dos graus de democracia digital explorados pelos portais governamentais brasileiros (GOMES, 2005; MARQUES, 2006; SILVA, 2005) e sul-americanos (BRAGATTO e VEIGA, 2006; BRAGA, 2007). O grau mais elementar, já em estágio bastante avançado em âmbito federal e em algumas esferas estaduais, inclui a oferta de informações sobre serviços de utilidade pública (como pagar impostos, obter documentos pessoais e certidões etc) e a efetiva prestação de serviços.

Graus mais complexos são, justamente, aqueles que contemplam a participação em processos de formulação de políticas, que podem envolver desde a mera manifestação de opiniões individuais ou setoriais sobre a agenda pública de áreas específicas, como um fórum online, até a efetiva inserção organizada em um processo de consulta pública. Neste último caso, a própria legitimidade de um governo passa a ser avaliada pela disposição ao diálogo que ele oferece, comprometendo-se a se sujeitar às inclinações e preferências objetivamente detectadas em torno de questões essenciais para a política então em discussão.

Silva, em pesquisa sobre os graus de democracia digital existentes em 24 portais de capitais brasileiras, detecta a ocorrência, principalmente, da oferta de informações, e também de esparsos mecanismos de prestação de serviços dentro da relação entre fazenda pública e contribuinte. Formas de ouvir o cidadão foram encontradas em metade da amostra estudada, mas de maneira limitada, apenas na forma de recepção de críticas não publicadas no portal. A inserção do cidadão para por aí: "não há sondagens temáticas, do tipo discursiva, sobre assunto de interesse”, assinala Silva (2005, p. 462). “Não há 'espaço' público (do tipo fóruns online ou mural de críticas) onde o cidadão possa enviar, ler e comentar as críticas 
ROTHBERG, D. Por uma agenda de pesquisa em democracia eletrônica...

dos seus pares, de forma a possibilitar um grau potencialmente maior de intervenção dialógica da opinião pública, na busca de maior transparência dos atos administrativos" (Idem, p. 463). Conclui-se então pela "sub-utilização das potencialidades democráticas destas tecnologias pelos governos das maiores cidades brasileiras", indica o autor ( Idem, p. 465). "Não há ainda indícios de um tipo de participação política mais sofisticada no âmbito da esfera governamental das capitais brasileiras que indiquem o emprego das tecnologias da comunicação para um efetivo papel da esfera civil na produção da decisão pública" (Idem, p. 465).

Na esfera dos websites do governo federal a situação é um pouco melhor. Bragatto e Veiga (2006) avaliaram as iniciativas de governo eletrônico na esfera federal em 2004 e indicam que, ainda que as tecnologias da comunicação e da informação sejam usadas principalmente na divulgação de informações institucionais, 6,81\% das páginas pesquisadas oferecem formas de participação na definição de agendas públicas, como sondagens de opinião e oportunidades para a manifestação de críticas na forma de consultas públicas.

Marques e Miola, em pesquisa sobre os websites da Câmara dos Deputados e das Assembléias dos cinco mais populosos estados de cada região brasileira (Bahia, Goiás, Pará, Rio Grande do Sul e São Paulo), indicam, a respeito da amostra sondada, que "as possibilidades oferecidas pela Internet vêm sendo aproveitadas de modo insuficiente" (MARQUES e MIOLA, 2007, p. 18). "A ferramenta mais recorrente a implicar algum tipo de interação se refere ao oferecimento de endereços de e-mail para que os usuários entrem em contato", detalham os autores (Idem, p. 18). "O único site a oferecer formas mais consistentes de participação deliberativa, implicando troca pública de razões, foi o da Câmara dos Deputados, através da realização de chats e de fóruns para discussão de proposições legislativas em andamento" (Idem, p. 18).

Pode-se dizer também, em termos gerais, que no Brasil a concentração de poder, a existência de redes sociais marcadas por sistemas de dominação e controle e as desigualdades de acesso à internet e de habilidades para um uso mais produtivo da rede são obstáculos ao uso democrático das novas tecnologias que precisam ser superados para se aproveitar o potencial das novas tecnologias, sustenta Frey (2003).

Lições sobre como usar a internet em benefício da cidadania vêm de experiências de democracia eletrônica no âmbito dos países da OCDE (Organização para a Cooperação e Desenvolvimento Econômico). "A provisão online de informação é pré-condição essencial para o engajamento, mas quantidade não significa qualidade", assinala pesquisa da $\operatorname{OCDE}$ (2003, p. 9, tradução do autor). "Promoção ativa e moderação adequada são chaves para consultas online efetivas", sustenta o documento, ao traçar um panorama da utilização das ferramentas da área pelos países-membros, que se baseiam no suposto aqui delineado: o 
"engajamento de cidadãos na produção de políticas públicas é um investimento sólido no desenho e na oferta de políticas melhores e um elemento central de boa governança" (OCDE, 2003, p. 9).

Finlândia e Itália são países com experiências de cidades que exploram a rede para consultar os cidadãos, indica Frey (2002), principalmente através de fóruns com diferentes tipos de moderação que são utilizados pelas autoridades municipais como meio de sondagem de opinião.

A Inglaterra destaca-se, entre os países da OCDE, pela realização freqüente de consultas online com elevados níveis de informação colocados à disposição para subsidiar a participação. Os primeiros experimentos na área começaram em 1998. Já em 2002 houve dez consultas online no âmbito do Parlamento britânico, arquitetadas a fim de incentivar a expressão de posicionamentos consistentes. "Ao invés de simplesmente criar um web fórum e convidar o público para dizer algo sobre aquilo, como em um programa online de entrevistas ao vivo, essas consultas foram desenhadas para recrutar participantes com experiência ou expertise em relação às questões específicas da política pública", detalha Coleman (2004, p. 3, tradução do autor). Sob o foco das políticas então consultadas, estiveram questões diversas como violência doméstica, tributação, comunicações e pesquisas com células-tronco.

Coleman (2004) enfocou propriamente duas das dez consultas realizadas em 2002 (violência doméstica e comunicações). Um dos objetivos foi verificar se a amostra repetiria os resultados de pesquisas anteriores que avaliaram negativamente a qualidade da informação antes constatada em chats e fóruns online, então marcados por superficialidade e, ao invés de deliberação produtiva, discussão aparentemente sem fundamentos ou conclusões lógicas. Os resultados obtidos por Coleman não sustentam a visão de que a participação online tende a ser preenchida por clichês e frases vazias; ao contrário, foi possível verificar consistência no debate estimulado pelas consultas pesquisadas.

Coleman também sugere que a qualidade da discussão pode ser incrementada com o emprego de tecnologias adequadas. Segundo o autor, o próprio Parlamento inglês reconheceu esse aspecto, com a publicação de um manual para orientar a realização de suas consultas públicas online (UNITED KINGDOM, 2002). Uma das recomendações é que, em cada caso, ao público deve ser dada informação com clareza sobre as balizas e os critérios desejáveis à participação em questão, em uma espécie de "contrato de consulta" (COLEMAN, 2004, p. 16). Isto tem resultado em importantes sínteses das questões consultadas, organizadas em documentos produzidos exclusivamente para cada circunstância, de maneira lógica e acessível, capazes de proporcionar uma participação competente. Além disso, a mediação entre os setores que participam de uma consulta, de maneira que suas contribuições sejam expressas com organização e transparência, é fundamental. "A deliberação online de políticas públicas deve ser 
ROTHBERG, D. Por uma agenda de pesquisa em democracia eletrônica...

mediada, baseada em regras e apropriadamente moderada a fim de contribuir para o processo democrático", advertem Coleman e Gøtze (2002, p. 20, tradução do autor).

Do estado atual de conhecimentos na área vem a percepção de que a aplicação das novas tecnologias não representa, per se, avanço no aprofundamento da democracia. Wong e Welch (2004) verificaram em que medida as experiências de governo eletrônico em 14 países significaram efetivamente incremento de accountability, entendida como a capacidade de responsabilização de um governo diante do público sobre sua própria performance. Um dos resultados sugere que governos autoritários tendem a restringir e controlar a informação disponível nos websites governamentais. Isto indica que a internet pode ser usada como meio de preservar poder de decisão política, e não compartilhar.

Mais recentemente, os determinismos que alimentavam, de um lado, apostas otimistas e, de outro, diagnósticos pessimistas, foram relativizados com as descobertas trazidas por estudos empíricos (WRIGHT e STREET, 2007). As pesquisas indicaram que a tecnologia de comunicação em rede não contém, em si, elementos para sustentar o otimismo daqueles que viam na internet uma plataforma para a troca de discussões razoáveis, capazes de concretizar, finalmente, o ideal de democracia deliberativa. Por outro lado, as investigações também abalaram o pessimismo daqueles que viam, em fragmentados e superficiais debates dispersos em fóruns online improvisados, a prova de que a polarização estéril seria o único resultado possível de discussões entre sujeitos protegidos pelo anonimato na rede - que falam muito, pouco escutam e se empenham na conversação apenas para reforçar dogmas, criticar opositores e culpar governantes por todas as tragédias que Ihes afetam.

A dicotomia era falsa, apontam Wright e Street (2007, p. 850). As soluções adotadas pelos planejadores dos websites que davam suporte aos fóruns é que eram os fatores responsáveis por este ou aquele uso da rede. As escolhas de design e de construção geral se revelam, exatamente, políticas, incentivando ou inibindo determinados meios de aproveitamento: "como a discussão é organizada dentro do meio de comunicação, ajuda a determinar se o resultado será deliberação ou cacofonia", isto é, "as possibilidades democráticas abertas (ou fechadas) por websites não são um produto da tecnologia em si, mas das maneiras pelas quais ela é projetada e construída" (WRIGHT E STREET, 2007, p. 850, tradução do autor).

No Reino Unido e na Europa, os meios de participação através da internet podem ser de três tipos, resumem Wright e Street (2007, p. 854-855). Em primeiro lugar, estão os fóruns sobre políticas públicas específicas, nos quais a inserção se dá diretamente no processo de sua formulação. Eles são focados em questões detalhadas, sobre as quais setores e indivíduos relevantes são chamados a oferecer contribuições, baseadas em extensos documentos elaborados para fundamentar a consulta e disponíveis online. 
Em segundo lugar, estão os fóruns abertos, nos quais qualquer um é convidado a dizer o que pensa, em geral sobre questões genéricas, mas definidas (não se pode dizer qualquer coisa sobre qualquer coisa). A discussão é livre, e não há garantia de que as opiniões serão aproveitadas, mas os governos têm estado atentos a esse tipo de conversação, porque ela pode ser usada como termômetro da receptividade de certas políticas.

Por último, estão fóruns mistos, que combinam soluções do primeiro e do segundo tipos. Um quadro recebe contribuições ligadas a questões de documentos específicos enquanto uma lista acolhe comentários gerais relacionados à problemática de fundo da política em questão.

Em todos os casos, o papel dos moderadores de fóruns e consultas se mostra essencial para o desenvolvimento de uma discussão produtiva, na qual os argumentos sejam claros, organizados e integrais o suficiente para que cada participante seja capaz de reconhecer a legitimidade das demandas alheias, situando sua própria pretensão de validade diante das expectativas dos outros.

As regras da moderação devem ser anunciadas com antecipação e visibilidade, a fim de evitar que os participantes as vejam como censura. A ação moderadora pode ser prévia, quando é exercida por pessoas que lêem todas as mensagens antes de elas serem postadas e as editam de modo a descartar trechos ofensivos, ou pós-publicação, quando os moderadores reagem a reclamações dos participantes e suspendem trechos ou mensagens inteiras de um fórum.

Coleman e Gøtze (2002, p. 17-18) sintetizam seis passos para a moderação adequada de esferas de discussão online: a) definir regras claras e transparentes, que abranjam a extensão permitida das mensagens, a não aceitação de linguagem ofensiva etc; b) garantir que o debate será intermediado de maneira não coercitiva, com neutralidade política e proteção de informações individuais; c) moderar o debate a fim de garantir que todo participante seja ouvido com respeito e de forma justa; d) ajudar os participantes a chegarem a novas conclusões, procurando evitar que apenas reciclem explicações superficiais; e) sintetizar o debate de maneira que os pontos principais e as conclusões centrais sejam apresentados a todos com organização e clareza; f) procurar dar alguma forma de retorno aos participantes, eles devem sentir que sua inserção foi válida.

No Reino Unido, descrevem Wright e Street (2007), muitos governos locais (city councils, de funções equivalentes às prefeituras brasileiras) contrataram as mesmas empresas para gerir soluções de software na área, gerando práticas mais ou menos padronizadas por várias regiões do país. As diferenças se explicariam por variações culturais locais. Autoridades que tendiam a valorizar a participação sobre o próprio processo de gestão de políticas ofereceram meios para tal inserção a partir de instrumentos online, com a apresentação de balizas para propiciar a expressão competente. Já outras localidades que rejeitavam tal participação, por considerá-la excessiva, apenas ofereciam ferramentas tecnológicas para a formação 
ROTHBERG, D. Por uma agenda de pesquisa em democracia eletrônica...

de um painel disperso de opiniões formuladas sem base adequada, que serviam apenas para orientar genericamente o processo político.

Em alguns casos, o potencial da internet foi simplesmente ignorado, a despeito das muitas experiências de uso intenso da rede para a discussão democrática em todo o país. Nos casos mais restritos, o website do conselho local apenas informava um endereço de e-mail para o cidadão se corresponder diretamente com o conselheiro de sua área. Mas, de forma geral, as consultas online sobre questões específicas se popularizaram fortemente no Reino Unido, superando inclusive os fóruns de discussão aberta sobre assuntos genéricos. "Em 2002, cerca de $62 \%$ dos websites dos conselhos locais estavam realizando consultas online, enquanto apenas $15 \%$ tinham um fórum de discussão", informam Wright e Street (2007, p. 858, tradução do autor).

As características técnicas não têm, naturalmente, o poder de determinar certo tipo de uso da tecnologia, mas podem significar incentivos poderosos na direção correta. Daí a natureza política das escolhas tecnológicas envolvidas na produção de uma ferramenta de discussão e consulta online. "A política da tecnologia, pode-se dizer, é uma parte central da história que vem sendo contada a respeito do potencial deliberativo da internet", comentam Wright e Street (2007, p. 855, tradução do autor), de forma que a "política está tanto no que é planejado como resultado da tecnologia, quanto nas escolhas políticas feitas quando se constrói sob encomenda uma tecnologia"(Idem).

O reflexo das decisões começa, na verdade, antes iniciar o processo de consulta. Em casos apurados pela pesquisa de Coleman (2002), eventos reais (não virtuais) foram promovidos para atrair os cidadãos para a deliberação online. Campanhas de publicidade nos meios tradicionais também foram úteis para estimular a participação. Até o texto de convite à inscrição em um website de fórum ou consulta já tem muito a dizer sobre o tipo de inserção esperada por um governo. Não pode ser simplesmente "diga o que quiser, envie críticas ou sugestões etc". A orientação deve ser precisa, anunciando que as posições devem ser manifestadas com argumentos completos e clareza expositiva. Para participar, deve ser exigido um registro de dados como nome, sobrenome, região de domicílio, profissão, organização da qual participa ou que representa, se for o caso, e outras informações pontuais ajustadas a cada caso (dezenas de dados podem ser úteis, dependendo da política em discussão: se tem filho em idade escolar, se fuma, se é usuário do transporte público etc). O sigilo sobre os dados deve ser assegurado. $\mathrm{Na}$ maioria dos casos, é vedado o anonimato. Mas também é preciso tomar cuidado para que o processo de registro não seja tão detalhado a ponto de inibir a cooperação.

Sobretudo, em certos casos é preciso antecipar que as contribuições devem estar ajustadas a eixos determinados que, em situações pesquisadas pelo autor, foram descritos e comentados em documentos preparados especialmente para o 
processo, às vezes com até uma centena de páginas, com argumentos de especialistas, mas em linguagem acessível. Algumas consultas sobre questões simples ("deve-se ou não impor proibição de estacionamento em determinada rua central”, por exemplo) são dirigidas a qualquer usuário e, portanto, assim devem ser anunciadas, desestimulando discussões genéricas sem relação direta com a pergunta central. Mas outras consultas, sobre temas complexos, devem sinalizar a quem se dirigem e apontar quais são os conhecimentos desejáveis como prérequisito à participação, fazendo referência aos documentos de orientação preparados e divulgados antecipadamente.

As escolhas envolvidas em uma solução na área resultam, de maneira geral, em formatos diferenciados de fóruns e consultas, que podem estimular determinada natureza da participação. Na avaliação da qualidade da inserção efetivamente realizada, as pesquisas da área têm procurado verificar certos aspectos, indicam Coleman (2002) e Wright e Street (2007).

É relevante saber, através da análise das centenas (ou milhares) de mensagens de um fórum online, por exemplo, se os participantes efetivamente oferecem idéias consistentes e informação pertinente à temática em questão, com dados e indicadores que fundamentem suas perspectivas, ou se apenas repetem clichês repercutidos pelo jornalismo comercial; se cada participação realmente envolve a troca de idéias, referindo-se objetivamente aos pontos de vista de outras pessoas, ou se consistem em meras reiterações de posições estereotipadas; se cada mensagem discute questões práticas de maneira substantiva ou se joga com trechos de outras mensagens para fazer comentários irônicos sobre supostas desvantagens de posições opostas; se as mensagens oferecem integralidade de argumentação suficiente para os debatedores conhecerem antecedentes e implicações de determinado posicionamento; e se os participantes estão dispostos a examinar as críticas às suas próprias posições, revendo-as se julgarem conveniente ou buscando outros argumentos para aclararem suas tendências.

Eventualmente, também é válido sondar, através de questionários, as pessoas que se registraram online para participar. Em uma experiência pesquisada por Coleman (2002), apenas um terço do total de registrados efetivamente postou uma mensagem. Aqueles que não o fizeram alegaram não ter tempo ou conhecimento para formular contribuições, mas afirmaram ter acompanhado o debate e dali extraído percepções úteis. O autor conclui que apenas observar as discussões também pode significar aprendizado relevante em termos de vivência democrática.

Também é importante saber como as contribuições foram incorporadas ao processo político. Em situações investigadas por Coleman (2002), parlamentares declararam que, diante de centenas de mensagens postadas sobre determinada questão, foi decisivo o trabalho de assessores na elaboração de sínteses dos pontos principais das propostas e comentários recebidos. Os métodos e critérios de 
ROTHBERG, D. Por uma agenda de pesquisa em democracia eletrônica...

sistematização empregados pelos assessores devem, assim, estar sob escrutínio dos pesquisadores.

Já para conhecer a qualidade da informação oferecida por consultas públicas online, a análise de conteúdo pode proporcionar uma avaliação quantitativa, enquanto a análise de enquadramento é capaz de fundamentar uma avaliação qualitativa.

A análise de conteúdo implica definir termos, sintagmas e outras unidades lexicais (e até mesmo componentes imagéticos ou televisuais) e verificar sua ocorrência nos textos enfocados, procedimento que deve ser conduzido de maneira a permitir inferências sobre temas e significados mais presentes. É uma técnica útil para descobrir e descrever o foco das preocupações de indivíduos, grupos e instituições em torno de determinadas questões políticas (KRIPPENDORFF, 1980; STEMLER, 2001). A importância dessa técnica permanece mesmo após o crescimento do volume de informações disponível na internet, ainda que sejam necessárias mudanças metodológicas para lidar com o potencial da difusão de informação pela rede, com seu uso de hyperlinks e conexões diversas (WEARE e LIN, 2000; KIM e WEAVER, 2002).

Já os enquadramentos podem ser caracterizados como "marcos interpretativos mais gerais construídos socialmente que permitem às pessoas obterem sentido dos eventos e das situações sociais" (PORTO, 2004, p. 78). Um enquadramento (framing) é construído através de procedimentos como seleção, exclusão ou ênfase de determinados aspectos e informações, de forma a compor perspectivas gerais através das quais fatos e circunstâncias são dados a conhecer. Trata-se de uma idéia central que organiza a realidade dentro de determinados eixos de apreciação e entendimento, que envolvem inclusive o uso de expressões, estereótipos, sintagmas etc.

Enquadramentos são matrizes cognitivas. O conceito nasce das pesquisas na área de psicologia que procuram compreender como os indivíduos organizam sua experiência, envolvendo as dimensões racional, afetiva, emocional etc do comportamento (KAHNEMAN e TVERSKY, 1984; GOFFMAN, 1986; GROSS e D’AMBROSIO, 2004).

Gamson e Modigliani (1989, p. 3) caracterizam os enquadramentos como "pacotes interpretativos" que conferem sentido a um assunto. Tais pacotes são capazes de "construir significados ao longo do tempo, incorporando novos eventos aos seus enquadramentos interpretativos" (Idem, p.4). Segundo esta ótica, "os enquadramentos não devem ser confundidos com posições a favor ou contra alguma medida política", assim como "nem todo pacote pode ser identificado com uma clara posição política" (Idem).

Embora a noção de framing tenha embasado pesquisas voltadas com freqüência à identificação de idéias e posicionamentos veiculados através da comunicação jornalística, estudos apontam que os enquadramentos contidos em 
esferas diversas como a conversação cotidiana e a comunicação oficial de governos são centrais para a formação de crenças políticas individuais e setoriais. Porque os frames caracterizam-se pela saliência de certas perspectivas de compreensão de fatos e eventos e pela exclusão de outras posições divergentes, eles orientam de maneira geral a construção de quadros interpretativos através dos quais as pessoas conferem significado ao mundo que as cerca (AZEVEDO, 2004; ENTMAN, 1993; DRUCKMAN E NELSON, 2003; NELSON e OXLEY, 1999; CHONG e DRUCKMAN, 2007).

\section{Conclusões}

Em torno de consultas e fóruns online existentes no âmbito dos websites governamentais brasileiros, cabe verificar a qualidade da inserção proporcionada no processo de produção e avaliação de políticas públicas, verificando-se o foco (quais aspectos da política pública em questão estão em consulta); a abrangência (quantos aspectos e qual a relevância das questões em consulta); as conseqüências (potencial efetivo de intervir no processo de gestão pública, considerando-se a dimensão das questões postas em consulta diante dos outros aspectos políticos ali envolvidos).

Além disso, as formas de mediação de debates e as macro-soluções de design utilizadas são determinantes para os resultados e precisam ser estudadas de perto. Ao mesmo tempo, é relevante avaliar a qualidade da informação, em seus aspectos de pluralidade e integralidade de dados e quadros interpretativos, oferecida pelos websites do governo federal brasileiro para subsidiar os processos de consulta pública de leis e regulamentos. Análises quantitativas (conteúdo) e qualitativas (frames) podem ser instrumentos úteis neste caso, e também para conhecer a função das inserções de cada participante (se lançam e trocam idéias, se apresentam dados e argumentos, se efetivamente discutem as proposições em questão ou se apenas expressam opiniões vagas e desqualificam posicionamentos alheios) e a pertinência do debate em geral (se proporciona a construção de posicionamentos balizados em dados e fatos objetivos ou se serve apenas para a exposição de comentários superficiais e irônicos, se gera realmente troca de idéias ou apenas dá vazão a monólogos e reforça preconceitos).

Desdobramentos recentes exemplificam como o governo federal brasileiro já pratica graus de democracia digital que acolhem a participação através de consultas públicas online sobre temas de grande relevância e alcance. Por exemplo: em julho de 2005, foi posta em consulta através da internet, pelo Ministério da Saúde, a Política Nacional de Atenção Integral à Saúde de Adolescentes e Jovens; em março de 2006, o Ministério da Cultura e o Ministério da Educação colocaram sob consulta o Plano Nacional do Livro e Leitura, que acolheu a manifestação de 
ROTHBERG, D. Por uma agenda de pesquisa em democracia eletrônica...

posicionamentos em torno de quatro eixos pré-definidos; em novembro de 2006, a Agência Nacional de Vigilância Sanitária (Anvisa) colocou sob consulta a Proposta de Regulamento Técnico de publicidade de alimentos com quantidades elevadas de açúcar, de gordura saturada, de gordura trans, de sódio e de bebidas com baixo teor nutricional; e, em julho de 2007, a Anvisa abriu, também através da internet, consulta para a Proposta de Regulamento Técnico de avaliação de segurança para o consumo humano de alimentos contendo ou consistindo de organismo geneticamente modificado (OGM) e de alimentos contendo ou consistindo de produtos derivados de animais alimentados com OGM ou com seus produtos derivados.

Eventos como estes, que proporcionam interação com o processo de produção de políticas de grandes conseqüências, indicam que o Estado brasileiro assumiu a função de utilizar a rede em benefício da ampliação dos locais onde se realiza a democracia no país. A política de implantação de governo eletrônico no âmbito do Ministério do Planejamento, Orçamento e Gestão incorpora, ao menos em princípio, "a promoção da participação e do controle social e a indissociabilidade entre a prestação de serviços e sua afirmação como direito dos indivíduos e da sociedade" (República Federativa do Brasil, 2003).

No entanto, não se sabe se os subsídios oferecidos sob o escopo de cada fórum ou consulta foram suficientes para fundamentar uma inserção competente nos espaços democráticos construídos pelas novas tecnologias, ou se as formas de mediação adotadas proporcionaram o fortalecimento de microesferas públicas em torno das questões discutidas. Reside aí um campo fértil para a pesquisa científica. 


\section{Referências Bibliográficas}

ABU-EL-HAJ, J. "O debate em torno do capital social: uma revisão crítica". BIB. Revista Brasileira de Informação Bibliográfica em Ciências Sociais. Rio de Janeiro, n 47, 1999.

AVRITZER, L.; COSTA, S. "Teoria crítica, democracia e esfera pública: concepções e usos na América Latina". Dados - Revista de Ciências Sociais, Rio de Janeiro, vol. 47, n 4, p. 703-728, 2004.

AZEVEdO, F. A. Agendamento da política. In: RUBIM, A. A. C. (org.). Comunicação e Política: conceitos e abordagens. São Paulo: Unesp; Salvador: Edufba, 2004.

BARBOZA, E. M. F. et al. "Web sites governamentais, uma esplanada à parte". Ciência da Informação, Brasília, vol. 29, n¹, p. 118-125, 2000.

BRAGA, S. S. "Podem as novas tecnologias de informação e comunicação auxiliar na consolidação das democracias? Um estudo sobre a informatização dos órgãos legislativos na América do Sul". Opinião Pública, Campinas, vol. 13, n¹, p. 1-50, 2007.

BRAGATTO, R. C.; VEIGA, L. "Participação democrática e novas tecnologias de comunicação: mapeando diretrizes políticas e o uso da internet pelos governos do Brasil e da Argentina". In: Anais do I Congresso Anual da Associação Brasileira de Pesquisadores de Comunicação e Política, Salvador, Universidade Federal da Bahia, 2006.

CASTELLS, M. Fluxos, redes e identidades: uma teoria crítica da sociedade informacional. In: CASTELLS, M. et al. Novas perspectivas críticas em educação. Porto Alegre: Artes Médicas, 1996.

COLEMAN, J. S. "Social capital in the creation of human capital". The American Journal of Sociology, vol. 94, Supplement: Organizations and institutions: sociological and economic approaches to the analysis of social structure, p. S95.S120, 1998.

COLEMAN, S. Hearing voices: the experience of online public consultations and discussions in UK governance. Londres: Hansard Society, 2002.

. "Connecting parliament to the public via the internet: two case studies of online consultations". Information, Communication \& Society, vol. 7, n 1, p. 1-22, 2004.

COLEMAN, S.; GØTZE, J. Bowling together: online public engagement in public deliberation. Londres: Hansard Society, 2002.

CHONG, D.; DRUCKMAN, J. N. "A theory of framing and opinion formation in competitive elite environments". Journal of Communication, vol. 57, p. 99-118, 2007. 
DAHLBERG, L. "The internet and democratic discourse: exploring the prospects of online deliberative forums extending the public sphere". Information, Communication \& Society, vol. 4, $n^{\circ} 4$, p. 615-633, 2001.

D'ANDRÉA, C. "Estratégias de produção e organização de informações na web: conceitos para a análise de documentos na internet". Ciência da Informação, Brasília, vol. 35, n 3, p.39. 44, 2006.

DRUCKMAN, J. N.; NELSON, K. R. "Framing and deliberation: how citizens' conversations limit elite influence". American Journal of Political Science, vol. 47, n 4, p. 729.745, 2003.

ENTMAN, R. M. "Framing: toward clarification of a fractured paradigm". Journal of Communication, vol. 43, n 4, p. 51-58, 1993.

FRASER, N. "Rethinking the public sphere: a contribution to the critique of actually existing democracy". Social Text, n²5/26, p. 56-80, 1990.

FREY, K. Governança eletrônica: experiências de cidades européias e algumas lições para países em desenvolvimento. In: EISENBERG, J.; CEPIK, M. (orgs.). Internet e política: teoria e prática da democracia eletrônica. Belo Horizonte: Editora UFMG, 2002.

. "Desenvolvimento sustentável local na sociedade em rede: o potencial das novas tecnologias de informação e comunicação". Revista de Sociologia e Política, Curitiba, vol. 21, p. $165 \cdot 185,2003$.

FURQUIM, T. A. "Fatores motivadores de uso de site web: um estudo de caso". Ciência da Informação. Brasília, vol. 33, n 1, p. 48-54, 2004.

GAMSON, W. A.; MODIGLIANI, A. "Media discourse and public opinion on nuclear power: a constructionist approach". The American Journal of Sociology, vol. 95, n 1, p. 1-37, 1989.

GITLIN, T. Public sphere or public sphericules? In: CURRAN, J.; LIEBES, T. Media, ritual, and identity. Londres: Routledge, 1988.

GOFFMAN, E. Frame analysis. Boston: Northeastern University Press, 1986.

GOMES, W. "A democracia digital e o problema da participação civil na decisão política". Fronteiras - Estudos Midiáticos. São Leopoldo, vol. 7, n 3, p. 214-222, 2005.

GROSS, K.; D'AMBROSIO, L. "Framing emotional response". Political Psychology, vol. 25, n 1 , p. 1-29, 2004. 
HABERMAS, J. Mudança estrutural da esfera pública: investigações quanto a uma categoria da sociedade burguesa. Rio de Janeiro: Tempo Brasileiro, 1984.

p.39-53, 1995.

. "Três modelos normativos de democracia". Lua Nova, São Paulo, n 36,

HALL, P. A.; TAYLOR, R. C. R. "As três versões do neo-institucionalismo". Lua Nova, São

Paulo, n 58, p. 193.223, 2003.

HELD, D. Models of democracy. Cambridge: Polity Press, 1996.

KAHNEMAN, D.; TVERSKY, A. "Choices, values, and frames". American Psychologist, vol. 39, $\mathrm{n}^{\circ} 4$, p. 341-350, 1984.

KIM, S. T.; WEAVER, D. "Communication research about the internet: a thematic metaanalysis". New Media \& Society, vol. 4, n 4, p. 518-538, 2002.

KLIKSBERG, B. "Seis teses não-convencionais sobre participação". Revista de Administração Pública. Rio de Janeiro, vol. 33, n 3, p. 7-37, 1999.

KRIPPENDORFF, K. Content analysis: an introduction to its methodology. Beverly Hills, CA: Sage, 1980.

LÜCHMANN, L. H. H. "A representação no interior das experiências de participação". Lua Nova, São Paulo, vol. 70, p. 139-170, 2007.

MAIA, R. C. M. Redes cívicas e internet: do ambiente denso às condições da deliberação pública. In: EISENBERG, José; CEPIK, Marco (org.). Internet e política: teoria e prática da democracia eletrônica. Belo Horizonte: Editora UFMG, 2002.

MARQUES, F. P. J. A. "Debates políticos na internet: a perspectiva da conversação civil". Opinião Pública, Campinas, vol. 12, n 1, p. 164-187, 2006.

MARQUES, F. P. J. A.; MIOLA, E. "Internet e Parlamento: um estudo dos mecanismos de participação oferecidos pelo Poder Legislativo através de ferramentas online. E-Compós. Vol. 9, 2007.

NELSON, T. E.; OXLEY, Z. M. "Issue framing effects on belief importance and opinion". The Journal of Politics, vol. 61, n 4, p. 1040-1067, 1999. 
OCDE. ORGANIZAÇÃO PARA A COOPERAÇÃO E DESENVOLVIMENTO ECONÔMICO. Promise and problems of e-democracy: challenges of online citizen engagement. França, 2003.

POLAT, R. K. "The internet and political participation: exploring the explanatory links". European Journal of Communication, vol. 20, n 4, p. 435-459, 2005.

PORTO, M. Enquadramentos da mídia e política. In: RUBIM, A. A. C. (org.) Comunicação e política: conceitos e abordagens. São Paulo: Unesp; Salvador: Edufba, 2004.

PUTNAM, R. D. "Tuning in, tuning out: the strange disappearance of social capital in America". PS: Political Science and Politics, vol. 28, n 4, p. 644-83, 1995.

REPÚBLICA FEDERATIVA DO BRASIL. Governo eletrônico: princípios e diretrizes, 2003. Disponível em: <https://www.governoeletronico.gov.br/o-gov.br/principios.> Acesso em: 22 nov. 2007.

SHAH, D. V. et al. "Information and expression in a digital age: modeling internet effects on civic participation“. Communication Research, vol. 32, n 5, p. 531-565, 2005.

SILVA, S. P. da. "Graus de participação democrática no uso da Internet pelos governos das capitais brasileiras". Opinião Pública, Campinas, vol. 11, n² 2, p. 450-468, 2005.

SIMÃO, J. B.; RODRIGUES, G. "Acessibilidade às informações públicas: uma avaliação do portal de serviços e informações do governo federal”. Ciência da Informação. Brasília, vol. 34, $\mathrm{n}^{\circ} 2$, p. 81-92, 2005.

STEMLER, S. "An overview of content analysis". Practical Assessment, Research \& Evaluation, vol.7, $\mathrm{n}^{\circ} 17,2001$.

WEARE, C.; LIN, W.-Y. "Content analysis of the World Wide Web: opportunities and challenges". Social Science Computer Review, vol. 18, n 3, p. 272-292, 2000.

WONG, W.; WELCH, E. "Does e-government promote accountability? A comparative analysis of website openness and government accountability". Governance: An International Journal of Policy, Administration, and Institutions, vol. 17, n², p. 275-297, 2004.

WRIGHT, S.; STREET, J. "Democracy, deliberation and design: the case of online discussion forums". New Media \& Society, vol. 9, n 5, p. 849-869, 2007. 
UNITED KINGDOM. HOUSE OF COMMONS INFORMATION SELECT COMMITTEE. Digital technology: working for parliament and the public. Londres, 2002.

VILELLA, R. M. Conteúdo, usabilidade e funcionalidade: três dimensões para a avaliação de portais estaduais de governo eletrônico na web. [Dissertação de Mestrado]. Universidade Federal de Minas Gerais, 2003.

Danilo Rothberg - danroth@uol.com.br

Recebido para publicação em janeiro de 2008.

Aprovado para publicação em março de 2008. 